\title{
O Socialismo Reformista e a Participaçao do Movimento Socialista na Ordem Democrática Capitalista
}

Daniel Wei Liang Wang

\section{Resumo}

O presente trabalho analisa dois grandes debates travados dentro do pensamento socialista nos séculos XIX e XX: entre organização partidária e espontaneidade e entre revolução e participação na democracia parlamentar.

A partir dos principais autores que participaram destes debates, juntamente com a experiência histórica, analiso como o socialismo reformista, que defendia a participação dos socialistas na democracia burguesa, foi fundamental nos países em que logrou sucesso para o desenvolvimento do Estado de BemEstar Social e, ao mesmo tempo, colaborou para enfraquecer os movimentos socialistas revolucionários.

A escolha pela participação no jogo democrático trouxe também mudanças dentro do próprio movimento em relação aos rumos que pretendia seguir.

Palavras-chave: participação, democracria, socialismo, bem estar social. 


\section{Organização Partidária ou Espontaneidade?}

Neste primeiro tópico, buscarei tratar a respeito do debate travado entre Lênin e Rosa Luxemburgo quanto à melhor forma de organização do movimento socialista. Opto por começar por este tema porque nele enxerga-se a preocupação de Lênin quanto às limitações de um movimento espontâneo do operariado - sem uma organização partidária com objetivos e métodos revolucionários - para se atingir o socialismo. A partir destas limitações apresentadas por Lênin pode-se entender parte do processo que culminou na inserção de grande parte do movimento operário na ordem democrática burguesa, o que reforçou os grupos socialistas de caráter reformista e esvaziou a alternativa revolucionária.

Lênin partia do pressuposto de que os operários não poderiam espontaneamente se organizar para travar a guerra revolucionária contra a minoria dominante. Isso porque os operários não tinham ainda consciência socialista e suas reivindicações, quando entregues às suas próprias forças, teriam apenas uma dimensão econômica. Buscar-se-ia apenas o atingimento de alguns resultados econômicos específicos e imediatos como melhores condições de trabalho, aumento de salário ou maior proteção social. Uma vez satisfeitas estas demandas econômicas, o movimento se esgotaria e não se direcionaria no sentido de lutar por mudanças políticas, ou seja, não buscaria a finalidade política última que Lênin esperava do movimento: o socialismo.

Lênin tecia severas críticas àqueles como Bernstein e Kautsky que defendiam uma organização do movimento operário em torno de sindicatos ou partidos que participassem da democracia parlamentar. Quanto ao sindicalismo, Lênin dizia que era o equivalente ao "abandono do socialismo" e representava "a escravidão ideológica do operariado" 2 .

Desta maneira, para Lênin, havia a clara necessidade de que uma minoria organizada (que estivesse fora dos limites estreitos da luta meramente econômica, do conflito entre operários e patrões) liderasse a massa operária para que o ímpeto de luta que surgia no proletariado devido às contradições do modo de produção capitalista não se esgotasse com resultados econômicos, mas que tivesse ressonâncias políticas e continuasse até a construção do socialismo. Essa minoria, organizada sob a forma centralizada de um partido revolucionário, teria como funções primordiais a conscientização política, educação e organização das massas operárias.

I cf. Vladímir Ilitch Lênin. Que Fazer?: As questões palpitantes do nosso movimento. São Paulo: Hucitec, I978, p. 32. 2 idem, ib. p. 32 . 
O partido deveria, então, dirigir a luta da classe operária não apenas para conseguir melhores condições para a venda da sua força de trabalho, mas também para a abolição da ordem burguesa, que obriga os desprovidos dos meios de produção a se venderem aos que os possuem. Esta luta não poderia se limitar a reformas econômicas - tendência espontânea da classe operária - mas deveria ser dirigida no sentido de se ampliar para buscar mudanças revolucionárias nas estruturas econômicas e sociais, pondo fim à opressão dos detentores do capital sobre a classe trabalhadora.

Rosa Luxemburgo, por sua vez, defendia a idéia que a classe operária poderia organizar-se espontaneamente para a construção do socialismo. Esta organização espontânea seria decorrente da própria consciência de classe e não de um conteúdo pronto levado por um determinado grupo para, a partir dele, organizar e educar os trabalhadores.

Ela criticava veementemente a subordinação de todo o movimento socialista às diretrizes emanadas de um centro todo-poderoso com ilimitado direito de controle e ingerência como advogara Lênin. Tamanho poder concentrado nas mãos de um grupo, o partido, coarctaria a espontaneidade do movimento das massas, o verdadeiro combustível da revolução, fazendo do partido uma organização conservadora.

Uma outra crítica de Rosa Luxemburgo questiona o comprometimento desta minoria que comanda o partido - formada essencialmente por intelectuais de origem burguesa e que agem não em virtude, mas a despeito de seu sentimento de classe - com a causa operária. Esses intelectuais, por sua origem não operária, estariam mais suscetíveis às tentações oportunistas do que os operários agindo em interesse próprio. Além do mais, existe o risco de que o movimento operário seja usado por intelectuais ambiciosos, mas mal sucedidos no jogo político burguês, como escada para subirem na carreira política.

Para Rosa Luxemburgo a organização das massas deve ser espontânea, pois a vinculação do movimento a um controle rígido e centralizado fará com que a história se repita, de forma que aqueles que um dia foram a vanguarda tornarse-ão a controladora da classe, passando de um poder do povo para um poder sobre o povo. Um partido nos caracteres idealizados por Lênin iria sufocar o movimento operário a uma elite sedenta por poder e que se firmará no poder por meio da burocratização do partido e do Estado. Para Rosa Luxemburgo "não há garantia mais eficaz contra os dirigentes oportunistas e as ambições pessoais do que a atividade revolucionária autônoma do proletariado, graças à qual o mesmo adquire o sentido das responsabilidades políticas" ${ }^{3}$.

3 cf. Rosa Luxemburgo. Socialismo e Liberdade. Porto: Escorpião, I975 p. 44. 
E quanto à experiência concreta da União Soviética liderada por Lênin, Rosa Luxemburgo criticava o excesso de centralismo nas decisões tomadas pelo partido que acreditava ter uma receita pronta, pensada por um punhado de intelectuais em torno de uma mesa redonda de escritório, para a construção do socialismo e que deveria ser inexoravelmente aplicada e seguida. Desta maneira, devido à inexistência de liberdade de imprensa, manifestação, reunião e participação política, as massas ficariam impossibilitadas de exercerem o seu papel histórico, o que impediria que o socialismo fosse construído da sua base, o operariado, mas outorgado, decretado de cima para baixo por uma elite burocrática. Rosa Luxemburgo previu que a União Soviética, da maneira como estava se organizando, não seria o governo de uma classe, mas de uma elite.

Importante apreender desta breve exposição é a preocupação de Lênin a respeito da necessidade de um partido centralizado com métodos e objetivos revolucionários na vanguarda do movimento operário. O contraponto com Rosa Luxemburgo serve para demonstrar os perigos inerentes a uma forma de organização tão poderosa e com enorme capacidade de controle sobre o movimento operário.

\section{Revolução ou Participação na Democracia Parlamentar?}

Apesar da divergência entre Rosa Luxemburgo e Lênin quanto à forma de organização do movimento socialista, se em volta de um partido centralizado ou na forma espontânea, ambos concordavam que a única forma de libertação da classe operária era por meio de uma revolução, pela negação completa das formas de organização econômica e política da ordem burguês-capitalista. $\mathrm{Na}$ visão destes autores não havia outra possibilidade de libertação da classe trabalhadora senão a revolução. Os defensores de movimentos socialistas reformistas que participavam da democracia parlamentar e apresentavam propostas de mudanças pontuais e graduais - que consistiam em melhorias econômicas, ou seja, participação maior na distribuição da riqueza gerada pelo capital - e participação na democracia parlamentar, dando paulatinamente maior peso para a classe trabalhadora na tomada de decisões, não eram vistos como companheiros de luta, mas como inimigos políticos.

Lênin acusava os movimentos reformistas, eminentemente os de caráter sindicalista, de escravizarem ideologicamente os operários e de abandonarem a luta socialista ${ }^{4}$. Rosa Luxemburgo, por sua vez, era extremamente cética quan-

4 cf. Vladímir Ilitch Lênin. Que Fazer?: As questões palpitantes do nosso movimento. São Paulo: Hucitec, I978, p. 32. 
to à idéia de que por meio de uma repartição mais justa dos ganhos dentro de um modo de produção capitalista pode-se, progressivamente, alcançar um meio de produção socialista. Para ela, o modo de distribuição de riqueza decorre do modo de produção da sociedade, ou seja, sem a destruição do modo de produção capitalista, nunca se vai conseguir chegar a um modo de distribuição socialista ${ }^{5}$.

Outra crítica de Rosa Luxemburgo era quanto à crença de que, por meio de uma democracia parlamentar burguesa, poder-se-ia levar a classe operária ao poder. Na análise de Rosa Luxemburgo, à burguesia, devido à política mundial conflituosa e à ascensão do movimento operário, já não interessava mais o modelo liberal-democrático por ela criado, o que faria da crença no desenvolvimento ininterrupto da democracia nos moldes burgueses uma miragem ${ }^{6}$. Ela questionava se a burguesia respeitaria as regras do jogo democrático se estas lhe desfavorecessem.

Karl Marx chama este tipo de socialismo reformista de socialismo conservador ou burguês, pois seria formado por "uma parte da burguesia que deseja compensar injustiças sociais para assegurar a continuidade da existência da sociedade burguesa"7. A "burguesia socialista" busca a manutenção da dominação burguesa concedendo alguns benefícios econômicos aos trabalhadores, mas mantendo-os dentro dos limites da sociedade existente, com abandono das idéias odiosas quanto à burguesia ${ }^{8}$. Para Marx a única saída para libertar o proletário das relações de produção burguesa é por meio da revolução ${ }^{9}$.

Como contraponto ao socialismo revolucionário defendido por Marx, Lênin e Rosa Luxemburgo, destacam-se as idéias de Eduard Bernstein, um dos maiores defensores de um socialismo reformista ou, nas palavras deste autor, da democracia social, que busca a libertação da classe trabalhadora por meio de conquistas econômicas, de reformas pontuais e graduais e das vitórias no jogo da democracia parlamentar.

A análise de Bernstein começa pela constatação de que para a realização do socialismo é imprescindível um alto grau de desenvolvimento capitalista e o exercício da soberania política pelo partido da classe trabalhadora ${ }^{\mathrm{I}}$.

5 cf. Rosa Luxemburgo. Reforma social ou revolução. Porto: Escorpião, I975, p. 92.

6 idem, ib. p. 94 .

7 cf. Karl Marx; Friederich Engels, O manifesto comunista. Rio de Janeiro: Paz e Terra: I998, capítulo 3.

8 idem, ib.

9 idem, $i b$.

IO cf. Eduard Bernstein. Socialismo evolucionário. Rio de Janeiro: Instituto Teotônio Vilela/Jorge Zahar, I997, p. 88 . 
Desta maneira, a primeira razão que Bernstein aponta para refutar a idéia de uma revolução socialista em sua época é que, até então, o desenvolvimento capitalista não tinha alcançado um grau suficiente que viabilizasse o socialismo. Como exemplo, o pensador alemão aponta que somente quando o capitalismo alcançar um grau de concentração das propriedades ${ }^{\mathrm{II}}$ - terras e empresas - na mão de alguns proprietários é que seria possível a administração delas pelo Estado socialista. As empresas e as terras precisam de um alto grau de centralização para facilitar a expropriação e a administração por parte de um governo socialista, pois a existência de vários pequenos empreendimentos e propriedades de terra inviabilizaria uma gestão planejada e centralizada.

Quanto à soberania política por parte da classe trabalhadora, ela pode ser atingida pela via parlamentar ou por meio de revolução. A opção de Bernstein é pela via da democracia parlamentar, com participação do operariado nas eleições e na organização de trade unions. A primeira linha de argumentação seguida por Bernstein tenta desqualificar o modo revolucionário lembrando que esta via implica necessariamente no uso da força e na destruição de vidas ${ }^{12}$ e que dentro do operariado existem graves diferenças de interesses e necessidades que impossibilitariam uma luta conjunta ou, na hipótese de se conseguir a união da classe para a luta revolucionária, essas diferenças acabariam aflorando após a remoção do inimigo comum: as classes proprietárias e governantes ${ }^{13}$. Além disso, o proletariado, até então, não representava a maioria da população, o que colocava em dúvida a força efetiva desta classe para um movimento de tamanha monta. Outro questionamento relevante levantado por Bernstein refere-se ao real interesse da classe proletária de se trocar um modo de produção capitalista por um socialista. Assim como o trabalhador rural está mais interessado em obter a sua própria terra do que em uma eventual coletivização dos latifúndios ${ }^{\mathrm{I}}$, talvez esse raciocínio sirva também para boa parte do proletariado.

A segunda linha de argumentação enaltece as qualidades de uma democracia parlamentar e valoriza as possibilidades da classe operária de se aproveitar desse instrumento como meio para alcançar seus objetivos. Em primeiro lugar

II Bernstein baseia-se em: Karl Marx; Friederich Engels. O manifesto comunista. Rio de Janeiro: Paz e Terra, I998, capítulo I, que já apontava a existência desta tendência do modelo capitalista de concentração da propriedade em poucas mãos.

I2 cf. Eduard Bernstein. Socialismo evolucionário. Rio de Janeiro: Instituto Teotônio Vilela/Jorge Zahar, I997, p. IO6.

I3 idem, ib. p. 9I.

I4 idem, ib. p. 93. 
porque, por haver igualdade de direitos de todos os membros da comunidade, permite a participação de todas as classes ${ }^{\mathrm{I}}$. Em outras palavras, "democracia é, em princípio, a supressão do governo de classe, embora não seja ainda a verdadeira supressão das classes" ${ }^{16}$, ela permite que membros de todas as classes participem, seja votando, seja sendo votado. Partindo desta premissa, Bernstein acredita que este modelo de democracia, juntamente com um maior grau de informação e discernimento da classe operária, transformará os representantes do povo em servidores do povo e permitirá à classe operária maior poder para reivindicar participação na riqueza social produzida pelo capitalismo. Ao se utilizar o caminho que o jogo democrático abre para que a classe trabalhadora ocupe espaços no cenário político, criam-se condições para buscar melhores condições de vida, por meio de serviços sociais, direitos sociais, econômicos e trabalhistas até o ponto que o trabalhador deixe de ser um proletário para ser um cidadão. Bernstein defende que o socialismo é um herdeiro do liberalismo, cabendo àquele desenvolver e superar este, mas não negá-lo. Isto deixa patente uma visão de continuidade e não uma visão de ruptura característica dos movimentos revolucionários socialistas. Para Bernstein a democracia parlamentar é uma condição e um meio para o socialismo.

Terminada esta breve exposição acerca das diferenças de concepção entre o socialismo revolucionário e o reformista, e fazendo uma ligação com a análise de Lênin a propósito dos limites de um movimento com objetivos que não ultrapassam a esfera da economia (abordado no tópico I do presente trabalho), tentarei mostrar como o desdobramento histórico e político das idéias de Bernstein confirmou, em certa medida, as de Lênin.

\section{Do Socialismo Reformista à Cidadania Social e ao Welfare State}

\section{1. Estado burguês frente aos movimentos socialistas}

O socialismo reformista nos moldes defendidos por Bernstein tinha, por razões óbvias, melhores condições do que o socialismo revolucionário de prosperar dentro de um Estado liberal-burguês. Não só eram menos combatidos

I5 Eduard Bernstein trabalha com um conceito de democracia parlamentar que inclui o sufrágio universal. I6 cf.Eduard Bernstein. Socialismo evolucionário. Rio de Janeiro: Instituto Teotônio Vilela/Jorge Zahar, I997, p. II3. 
por terem reivindicações mais moderadas e que não negavam a ordem burguesa, como também muitas de suas propostas eram vistas com bons olhos pela elite dominante que, na impossibilidade de reprimir as demandas da classe operária, optou por incorporá-las ao sistema capitalista em termos compatíveis com o padrão de acumulação do capital.

Frente às contradições inerentes ao modo de produção capitalista e à ascensão de movimentos socialistas revolucionários, a ordem burguesa, quando não conseguia ou não via vantagens em reprimir, optou por aumentar a participação do proletariado na distribuição da riqueza social e/ou no jogo político da democracia parlamentar.

Um exemplo de sucesso na aplicação desta estratégia é a Alemanha sob o comando de Bismarck, que antecipou algumas idéias do que viria ser conhecido como o Welfare State. A fim de se igualar e superar as outras potências européias, a Alemanha passou por um processo de rápida industrialização, o que teve como conseqüência natural a rápida formação de um proletariado. Este proletariado, inspirado nas idéias socialistas, logo começou a se organizar para contestar as condições de exploração que lhes eram impostas. A primeira maneira do governo de Bismarck de lidar com esta nova classe de demandas foi o enfrentamento e a coerção ${ }^{17}$, uma tática que se mostrou ineficiente. Optou-se, então, pela incorporação do operariado ao sistema por meio da concessão de alguns direitos trabalhistas e sociais, principalmente para algumas categorias mais estratégicas, como a dos ferroviários. Desta maneira, conseguia-se diminuir a quantidade e intensidade das revoltas dos trabalhadores, o que diminuía a produtividade. Esta forma de atuação também esvaziava o poder ${ }^{18}$ das novas organizações de cunho socialista revolucionário, pois o Estado atendia algumas demandas dos trabalhadores antes que elas virassem bandeiras de luta para grupos revolucionários. É a chamada "fuga para frente" que criou uma espécie de Welfare State de cima para baixo, o que desorganizou os movimentos que tentavam uma mudança de baixo para cima.

A paulatina absorção das classes trabalhadoras ao sistema capitalista e ao Estado que faz parte da sua superestrutura, por meio da ampliação da participação das massas no jogo democrático - o que inclui a ampliação do sufrágio e a garantia das liberdades públicas como liberdade de expressão, de associação, de ir e vir - e,

I7 Esta maneira de lidar com os movimentos operários contestatórios, que se repetiu em vários lugares do mundo, inclusive no Brasil durante a República Velha, é bem resumida na célebre frase Washington Luís: "Questão social é caso de polícia".

I8 Por "poder" entende-se aqui no sentido de capacidade de iniciativa. 
posteriormente, da concessão de direitos econômicos, sociais e trabalhistas é muito bem explicada por T.H. Marshall no livro Cidadania, classe social e status. Marshall faz uma análise do conceito contemporâneo de cidadania, que, na sua origem, marcadamente no século XVIII, tinha como núcleo apenas os direitos civis: direitos de liberdade e igualdade formal. Estes direitos igualavam perante a lei, mas não se refletiam na diminuição das desigualdades sociais e muito menos em melhoras na qualidade de vida dos trabalhadores. Entretanto, a partir da igualdade formal, das liberdades de manifestação e de associação em sindicatos e partidos, o movimento operário ganhou forças para reivindicar participação no exercício do poder político. As liberdades civis serviram de plataforma para lançar a luta pela ampliação dos direitos políticos. E, uma vez que os trabalhadores puderam não só reivindicar, mas também votar e ser votados, abriu-se espaço para a introdução de direitos sociais, econômicos e trabalhistas, criando o conceito de cidadania social e mudando a forma e as funções do Estado burguês, que passou de um paradigma liberal para o de um Estado social que, no século Xx passou a ser conhecido como Estado de Bem-Estar Social ou Welfare State.

Desta análise que Marshall faz da introdução dos direitos econômicos ${ }^{19}$, sociais e trabalhistas no ordenamento jurídico, podemos ver um exemplo de como a luta dos trabalhadores por melhores condições de vida institucionalizou-se dentro do Estado burguês. No momento em que a classe trabalhadora alcança algumas demandas econômicas e vê dentro da ordem burguês-capitalista a existência de possibilidades de maiores conquistas, a luta contra o Estado burguês esvazia-se e passa a ser uma luta por meio dele. Desta forma, o Estado consegue legitimidade perante as grandes massas e traz a estabilidade necessária para a acumulação capitalista.

É muito interessante a semelhança entre o modelo proposto por Bernstein e a análise feita por T.H. Marshall. Bernstein defendia o uso dos direitos civis e políticos pelo movimento operário e que a luta dos trabalhadores deveria ser por meio das liberdades civis e da participação na democracia parlamentar, o que, por fim, instauraria uma sociedade socialista. Já Marshall, por sua vez, descreve um processo semelhante, mas com uma grande diferença de que o seu objetivo final, apesar de diminuir o padrão da desigualdade social, não inclui acabar com o livre mercado e a sociedade de classes, como defendiam os socialistas reformistas.

E, de fato, na História do último século não há um único exemplo de um Estado que tenha se tornado socialista por meio da democracia parlamentar,

I9 T.H. Marshall fez essa análise pensando no contexto inglês, mas que serve como modelo analítico para a compreensão do fenômeno. 
contrariando a previsão de Bernstein. Um Estado de Bem Estar Social, um capitalismo domesticado, humanizado, com distribuição de renda e qualidade de vida para todos foi o máximo que se alcançou.

À guisa de conclusão deste item III, podemos afirmar que o Estado capitalista aceitou conviver com o socialismo reformista concedendo aos trabalhadores direitos políticos, sociais, econômicos e trabalhistas, talvez por apostarem na tese de Lênin de que o movimento operário, uma vez alcançados objetivos econômicos, não teria ressonância política no sentido de uma destruição da ordem capitalista. A burguesia optou por entregar alguns anéis para não perder os dedos.

\section{III.2. Os movimentos socialistas frente ao Estado burguês}

A construção do Estado de Bem Estar Social deu-se por meio de um processo que, principalmente no seu começo, testemunhou um interessantíssimo dilema enfrentado pelos movimentos socialistas: participar, ou não, do jogo democrático e, desta maneira, buscar os interesses da classe por meio das instituições políticas fazendo uso dos direitos políticos dos trabalhadores, mas, conseqüentemente, abdicando de uma "ação direta", de um confronto direto com a ordem burguesa.

Alguns grupos optaram por esta participação e se organizaram em partidos para participar das eleições e eleger representantes da classe trabalhadora. Optaram por fazer uso dos direitos políticos dos trabalhadores, ou lutar por estes direitos onde não existissem, para defenderem interesses da classe operária, para reivindicar direitos sociais e econômicos, prestação de serviços públicos, maior participação na riqueza gerada pelo capital e melhores condições de trabalho. Esta luta, travada na arena da democracia, também trazia um maior grau de legitimidade e segurança institucional para as conquistas da classe operária, traduzidas em termos de direitos. Além do mais, a representação nos governos e parlamentos protegia os movimentos socialistas da repressão ${ }^{20}$.

Entretanto, à parte de todos os benefícios alcançáveis pela participação política, havia um grande receio de que ela acabaria obstruindo a consecução do objetivo final, qual seja, a construção do socialismo. Além dos argumentos já trazidos por Lênin e Rosa Luxemburgo que demonstram essa preocupação ${ }^{2 \mathrm{I}}$, Adam Przeworski traz outros também muito elucidativos a respeito desta questão.

Przeworski faz uma análise de como a lógica do funcionamento do jogo eleitoral foi, paulatinamente, mudando táticas e conceitos dos socialistas. A co-

20 Adam Przeworski. Capitalismo e social-democracia. São Paulo: Companhia das Letras, I995, p. 25. 2I Ver item II. 
meçar pela necessidade de atrair votos de pessoas não pertencentes à classe operária. Isso porque a previsão de Marx de que o proletariado se tornaria maioria na população não se mostrou verdadeira, tornando inviável a vitória eleitoral de um partido que tivesse propostas de interesse exclusivo do operariado, buscando apenas nessa classe os votos para ganhar um pleito eleitoral. Os partidos socialistas, à medida que almejavam maiores sucessos eleitorais, precisavam tratar dos interesses de outros grupos, como pequenos burgueses e profissionais liberais, tanto para angariar votos quanto para, em caso de vitória, formar alianças e coalizões necessárias para viabilizar um governo.

Muito importante também ressaltar que o socialismo não era unanimidade nem entre os próprios operários que o movimento dizia representar ${ }^{22}$. Para muitos trabalhadores, segundo Przeworski, "não era evidente que uma melhora em suas condições requeria a abolição do próprio sistema salarial" ${ }^{23}$. A teoria socialista seria por demais abstrata para os trabalhadores, que se sentiriam mais atraídos por conquistas mais imediatas e tangíveis do que por promessas de longo prazo. Os partidos socialistas, portanto, para angariar votos dentro da própria classe operária, precisariam ter um enfoque muito grande nas conquistas econômicas de curto prazo.

Houve também a necessidade dos partidos de abandonar, e até mesmo combater, as táticas consideradas ilegais de luta e os métodos inadmissíveis dentro de uma ordem democrática. Primeiramente por uma questão de coerência, já que uma vez que um movimento se propõe a participar do jogo da democracia parlamentar e usufruir de todos os benefícios que ele oferece, este movimento deve também aceitar as regras e não ignora-las quando lhe convém. E, em segundo lugar, também para ganhar a confiança da pequena burguesia, dos profissionais liberais ou de operários não simpáticos ao socialismo, cujos votos os partidos socialistas não conquistariam se não demonstrassem compromisso com as regras e limites do jogo eleitoral parlamentarista ${ }^{24}$.

Entretanto, para os socialistas que ingressaram na política burguesa, essas questões eram problemas de curto prazo, apenas pequenas pedras no caminho para se alcançar o poder político e realizar as mudanças em direção ao socialismo. O compromisso era ainda com a classe operária. Na visão dos socialistas, as conquistas obtidas por meio da democracia parlamentar, além de melhorarem a vida dos operários e os trazer para o seu lado, facilitariam o caminho para o alcance do

22 Argumento muito parecido com o apresentado por Bernstein. Ver nota de rodapé I4 .

23 Adam Przeworski. Capitalismo e social-democracia. São Paulo: Companhia das Letras, I995, p.37.

24 idem, ib. p. 28. 
objetivo final, fazendo de cada conquista um tijolo na construção da obra final, o socialismo. Na visão destes socialistas, como Kautsky e Bernstein, as medidas imediatas não representavam qualquer tipo de perigo para a consecução do objetivo final, como tanto temia Lênin. Pelo contrário, seriam etapas em direção a uma completa reestruturação da sociedade. Przeworski afirma que para o movimento democrático socialista "reforma" e "revolução" não eram conceitos antagônicos, sendo que a "reforma" seria um meio para o fim último, a "revolução". Eles se consideravam reformistas em relação ao meio, mas viam-se como revolucionários em relação aos fins que queriam atingir.

Vale aqui ressaltar a importância de se trazer os operários para o lado dos socialistas. Dentro do sistema capitalista prevalece uma lógica de competição entre os próprios trabalhadores por vantagens econômicas, como no exemplo de um trabalhador desempregado que aceita receber um salário mais baixo ao procurar um emprego e, conseqüentemente, retira a vaga de um outro trabalhador que recebia um valor maior. Este tipo de comportamento teria como conseqüência a diminuição geral dos salários. Uma das funções do partido socialista na democracia parlamentar seria, então, a de incutir nos trabalhadores uma consciência de classe e impedir que interesses individuais de cada operário se sobrepusessem aos interesses de toda a classe. Buscava-se, desta maneira, suprimir a competição interna dentro da classe e uni-la para que se atingisse os interesses comuns por meio de uma consciência de classe.

No entanto, todas essas mudanças operadas dentro dos partidos socialistas, que seriam apenas obstáculos de curto prazo, acabaram por mudar a própria visão política do partido. Na década de I920, houve uma mudança de estratégia dos principais partidos socialistas na Europa. Abandonou-se a bandeira do socialismo e, no seu lugar, levantou-se a bandeira do "bemestar social". A luta por justiça social, por direitos econômicos, sociais e trabalhistas, por distribuição de renda e por políticas públicas voltadas para os menos favorecidos já não se travaria contra o capitalismo, mas estes objetivos seriam alcançados através de um capitalismo fortemente regulado por um Estado capaz de distribuir riquezas e proteger os trabalhadores contra as vicissitudes do modo de produção capitalista. Este novo tipo de Estado é o que hoje chamamos de Welfare State (Estado de Bem-Estar Social). Um Welfare State não é um governo socialista, pois sua infra-estrutura é capitalista (nele estão garantidos o direito de propriedade sobre os meios de produção e o mercado), e no momento em que o Welfare State torna-se a bandeira e o projeto político dos partidos socialistas, não há mais espaço para um projeto socialista. Przeworski define muito bem este novo projeto como um "compromisso fundamental com aqueles que ainda eram denunciados como ex- 
ploradores, mas era economicamente viável, socialmente benéfico e, talvez mais importante, politicamente praticável sob as condições democráticas”.

Para ter sucesso, o Welfare State depende de um funcionamento eficiente do capitalismo nacional. Isso ocorre porque, em regra, cabe à iniciativa privada, por ser detentora dos meios de produção, a produção de riqueza. Um capitalismo em crescimento garante o pleno emprego, um dos fundamentos do Welfare State. Além do mais, uma parcela da riqueza produzida pelo capitalista é arrecadada pelo Estado, pela tributação, para distribuir ao resto da população por meio de direitos e políticas públicas sociais de que depende o bem-estar da população economicamente menos favorecida. O Estado de Bem Estar Social, portanto, não pode se opor ao capitalista, pois depende dele. Pelo contrário, deve proteger os investimentos do capitalista e ajudá-lo a aumentar sua produtividade e competitividade. Os partidos socialistas no governo, se prejudicassem o bom funcionamento do capitalismo, teriam inviabilizado o projeto de um Estado de Bem Estar Social, ou, antes disso, não conseguiriam ganhar mais eleições, pois perderiam votos entre os próprios trabalhadores pelo fato de terem diminuído o seu bem-estar social.

Muito interessante notar que um movimento que tinha inicialmente a intenção de chegar ao socialismo por meio de reformas acabou dependente de um bom funcionamento do capitalismo, da lucratividade da atividade capitalista. A social-democracia teve que admitir e proteger a propriedade privada dos meios de produção para, em troca, conseguir a colaboração dos capitalistas para a distribuição de parte da lucratividade do capital.

\section{Conclusão}

O resultado da participação de partidos socialistas na democracia parlamentar não foi, como idealizavam os teóricos do socialismo reformista, a transformação da sociedade capitalista em socialista. Norberto Bobbio lembra que a experiência histórica nos mostra que um Estado capitalista nunca se transformou em socialista democraticamente por meio das regras do jogo da democracia parlamentar ${ }^{25}$. O máximo que se alcançou foi o Welfare State, que trouxe melhora significativa na vida da classe trabalhadora nos lugares em que foi implementado com sucesso, mas que se sustenta sobre um modo de produção capitalista e não apresenta perspectivas de que o seu aprofundamento possa levar à construção do socialismo.

25 Norberto Bobbio. Qual socialismo? Rio de Janeiro: Paz e Terra, I983, p. 33. 
Desta constatação podemos concluir que Lênin acertou na sua análise a respeito dos limites de um movimento que não praticasse os métodos revolucionários de superação da ordem capitalista. Os socialistas reformistas, que se organizaram em partidos e sindicatos nunca chegaram ao poder como classe organizada e disposta à implantação do socialismo. Aliás, o objetivo inicial de se chegar ao socialismo por meio da democracia parlamentar foi deixando de ser um projeto de governo dos partidos socialistas à medida que se aprofundou a sua participação na democracia.

Isso ocorreu por uma série de motivos. Além daqueles já citados a respeito das concessões que deveriam ser feitas para obter sucesso nos pleitos eleitorais, podemos dizer também que uma revolução socialista dificilmente teria apoio de um operariado que gozasse de um bom trabalho e de uma boa rede de proteção social. Uma vez satisfeita algumas demandas econômicas, o proletariado estaria pouco propenso a grandes mudanças que, além de muito difíceis de realizar, não traziam qualquer tipo de segurança de que as conquistas já obtidas seriam garantidas ou mesmo ampliadas. Essa lógica foi percebida e aplicada já por Bismarck para proteger a Alemanha dos ventos revolucionários socialistas ${ }^{26}$.

O exemplo da Revolução Russa corrobora parte da tese de Lênin, pois ela foi realizada por um partido que lançava mão de métodos revolucionários, de uma ação direta de um grupo organizado e centralizado contra a classe dominante econômica e politicamente. A experiência soviética, entretanto, confirmou também as previsões de Rosa Luxemburgo ${ }^{27}$, além de assombrar o mundo pelo caráter totalitário do regime soviético. O partido realmente tomou o poder, como previra Lênin, mas criou um regime que de socialista tinha apenas o nome, pois era mais repressor que qualquer regime despótico e mais explorador que muitos regimes liberal-burgueses. Como disse Bakunin: "O governo da maioria das massas populares se faz, porém, por uma minoria privilegiada de marxistas, antigos operários que tão logo se tornem governantes cessarão de ser operários e não mais representarão o povo, mas a si mesmos. Quem duvida disso não conhece a natureza humana”. O método revolucionário mostrou-se, na União Soviética, eficiente para se tomar o poder, mas não se mostrou capaz de construir o socialismo.

Historicamente, tanto o método revolucionário quanto o reformista não conseguiram atingir o socialismo. Mas enquanto aquele é uma triste lembrança de um período totalitário, este deixa como herança um modelo

26 Ver item III.I.

27 Ver item I. 
de Estado respeitador de direitos civis, políticos, sociais, econômicos e trabalhistas ${ }^{28}$.

O final do século Xx, testemunha da queda do muro de Berlin e da crise do Estado de Bem Estar Social faz com que a esquerda do começo do século XXI passe por uma crise de identidade. A reflexão sobre a experiência histórica brevemente narrada nesse presente trabalho pode servir de referência para a esquerda de hoje redefinir os objetivos a serem alcançados e os meios a serem utilizados ${ }^{29}$.

\section{Referências Bibliográficas}

Arrtahe, Marta. "Emergência e desenvolvimento do Welfare State: teorias explicativas".

Bernstein, Eduard. Socialismo evolucionário. Rio de Janeiro: Instituto Teotônio Vilela/Jorge Zahar, I997.

Bobвio, Norberto. Qual socialismo?. Rio de Janeiro: Paz e Terra, I983.

Gastro, Paulo de. Rosa Luxemburgo, socialismo e liberdade. Rio de Janeiro: Forum, I968.

Ianni, Octavio. Marx. Coleção Grandes Gientistas Sociais. São Paulo: I988.

28 É necessário fazer a ressalva de que, assim como previu Rosa Luxemburgo, em muitos casos as elites não respeitaram os resultados eleitorais (ver item "Revolução ou Participação na Democracia Parlamentar?"). Vide o exemplo do Chile, em que o governo socialista de Allende, eleito democraticamente, foi derrubado por um golpe militar.

29 Muito informativo a respeito do assunto é a entrevista concedida pela então candidata a presidente Heloísa Helena do PSOL ao programa Roda Viva da TV Cultura em I2 de Junho de 2006. Heloísa Helena, assumidamente socialista, candidata à presidência da república, apresentava um discurso em que mostrava preocupação com as questões sociais, mas que não deixava de ressaltar seu compromisso com as instituições, o respeito à Constituição e aos marcos normativos, além de dar ênfase muito grande ao tema do crescimento econômico. 
O Socialismo Reformista e a Participação do Movimento Socialista Na Ordem...

LenIN, Vladimir Ilitch. Que fazer? : as questões palpitantes do nosso movimento. São Paulo: Hucitec, I978.

Luxemburgo, Rosa. Reforma social ou revolução. Porto: Escorpião, I975.

Marshall, T.H. Gidadania, classe social e status. Rio de Janeiro: Zahar, I967.

MarX, Karl; Engels, Friederich. O manifesto comunista. Rio de Janeiro: Paz e Terra: 1998.

Przeworski, Adam. Capitalismo e social-democracia. São Paulo: Companhia das Letras, I995.

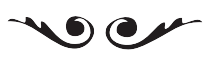

DANIEL Wei Liang Wang é graduado em direito pela USP.

E-mail: danielwei_cn@yahoo.com.br. 